\title{
Um olhar errante sobre as intervenções urbanas em Porto Alegre ${ }^{\star}$
}

\author{
Guilherme Augusto Flach, (D) $\star \star$ Simone Mainieri Paulon \\ Universidade Federal do Rio Grande do Sul, Porto Alegre, RS, Brasil
}

Resumo

\begin{abstract}
Este artigo tem por objetivo explorar as intervenções urbanas na cidade de Porto Alegre e seus efeitos sobre os modos de vida na cidade. Tais intervenções podem estar em sintonia com a arte urbana, o a(r)tivismo, o efêmero, o urbanístico, a arquitetura e os movimentos de ocupação dos espaços públicos. A metodologia é traçada através da cartografia e da errância, fazendo do corpo do pesquisador superficie aos acontecimentos. Constrói-se, assim, uma narrativa acerca das forças que compõem a cidade a partir dos efeitos de tais intervenções no tecido urbano. Frente aos imperativos homogeneizadores das cidades - atrelados às premissas do biopoder e da produção capitalística, captam-se efeitos de pausa em uma rotina acelerada, que possibilitam encontros e dissipam o medo urbano. As intervenções urbanas promovem a abertura de limiares que se fazem possibilidade de criação e defesa da potência de vida, entrelaçando-se à produção do novo nas subjetividades emergentes.
\end{abstract}

Palavras-chave: cidade; intervenção urbana; narrativa; Porto Alegre; errância.

\section{A wandering look at urban interventions in Porto Alegre}

\begin{abstract}
This article aims to explore urban interventions in the city of Porto Alegre and its effects on the ways of life in the city. Such interventions may be in tune with urban art, activism ar, ephemeral, urbanistic, architectural and occupational movements of public spaces. The methodology is traced through cartography and wandering, making the researcher's body surface to events. Thus, a narrative about the forces that compose the city is constructed from the effects of such interventions in the urban environment. In the face of the homogenizing imperatives of cities - linked to the premises of biopower and capitalist production, pause effects are found in an accelerated routine that allow encounters and dissipates urban fear. Urban interventions promote the opening of thresholds that make it possible to create and defend the potency of life, intertwining with the production of the new in emerging subjectivities.
\end{abstract} Keywords: city; urban intervention; narrative; Porto Alegre; wandering.

\section{Una mirada errante a las intervenciones urbanas en Porto Alegre}

\author{
Resumen
}

Este artículo tiene como objetivo explorar las intervenciones urbanas en la ciudad de Porto Alegre y sus efectos en los estilos de vida de la ciudad. Tales intervenciones pueden estar en sintonía con el arte urbano, el a(r)tivismo, lo efimero, lo urbano, la arquitectura y los movimientos de ocupación de los espacios públicos. La metodología se traza a través de la cartografia y la deambulación, haciendo que el cuerpo del investigador aflore a los eventos. Así, se construye una narrativa sobre las fuerzas que componen la ciudad a partir de los efectos de tales intervenciones sobre el tejido urbano. Frente a los imperativos homogeneizadores de las ciudades, vinculados a las premisas del biopoder y la producción capitalista, los efectos de pausa se capturan en una rutina acelerada, que posibilita encuentros y disipa el miedo urbano. Las intervenciones urbanas promueven la apertura de umbrales que permiten crear y defender el poder de la vida, entrelazándose con la producción de lo nuevo en subjetividades emergentes.

Palabras clave: ciudad; intervención urbana; narrativa; Puerto Alegre; errante.

\section{Introdução}

O corpo de um cidadão-pesquisador chegou há oito anos na capital gaúcha. Corpo que já foi forasteiro, aventureiro e errante. Deparou-se com novas vias, percebeu diferenças, construiu rotinas e encontros. Hoje está mais familiarizado com a nova cidade, ora seguindo seus fluxos, ora tentando resistir a eles. Assaltos, trânsito, distâncias... Já tem um maior conhecimento de alguns espaços e suas singularidades, o que não determina que neles se sinta mais à vontade. São bairros em que transita com maior frequência, que já tiveram seus becos desbravados, revelando boas surpresas que motivam a busca de outras.

\footnotetext{
^ $\mathrm{O}$ presente artigo resultou da reelaboração de parte de uma dissertação de mestrado que contou com o apoio da Capes.

$\star \star$ Endereço para correspondência: Universidade Federal do Rio Grande do Sul, Instituto de Psicologia. Av. Ramiro Barcellos, 2600, sala 314. Santana - Porto Alegre, RS - Brasil. CEP: 90035003. E-mails: guiflach@hotmail.com, simonepaulon@gmail.com

Os dados completos dos autores encontram-se ao final do artigo.
}

Praças, bares, carnavais... Em visitas à sua cidade natal, sempre está atento às transformações que vai encontrando: novas casas e prédios, algumas demolições, novas ruas e cores, novos problemas e soluções. Com exceção do tamanho e da quantidade de habitantes, nada é muito diferente de Porto Alegre, lugar que esse corpo escolheu para viver. As mudanças e seus ecos parecem ser o ponto que torna as cidades tão parecidas.

Como as demais cidades contemporâneas, esta também parece regida por dois grandes imperativos: circule e tema. Num contexto abarrotado de grades e muros com a presunção de nos proteger de quase tudo, encontram-se também calçadões, avenidas e highways como espaços-passagem acelerados onde o outro, o encontro, o parar, precisam ser evitados (MIZOGUCHI, 2009). O medo se dispersa na cidade: o criminoso pode ser qualquer um, expor-se é perigoso. Os postes de iluminação distribuídos 
nas ruas ajudam a delinear seus fluxos e seus formatos. São novos formatos que passam a sediar as aventuras e os perigos do que antes ficava de fora dos muros protetores das cidades. Para Rodrigo Silva (2012), a cidade deixa de ser uma ilha e passa a ser uma galáxia policêntrica. A proteção também se dilui em meio às estradas, às luzes, à eletricidade que percorre os circuitos urbanos. "O paralelismo das rodovias apenas multiplica assombrosamente a circularidade das muralhas, esse é seu segredo" (SILVA, R., 2012, p. 24). Substituem-se as entradas e saídas da cidade pela circulação.

Sob o imperativo do movimento, essa nova cidade inaugura uma nova forma de comportamento pautada nas trajetórias e fechada em sua própria rotatória. O movimento errante encontra um espaço desqualificado nas metrópoles por conta do medo. Os moradores vivem nessa contradição de múltiplas informações e opções, uma velocidade sempre crescente, seguindo uma ordem para se deslocarem de acordo com uma produção capitalística em meio a caminhos cada vez mais obstaculizados, relações escassas e desconfiança constante quanto aos espaços (SILVA, R., 2012). Sinos, cores, semáforos regulam e dividem o tempo, no qual "o ócio torna-se inimigo do aperfeiçoamento da alma” (BAPTISTA, 2009, p. 48).

$\mathrm{O}$ lar e o trabalhar confundem-se num mesmo ambiente, diminuindo a necessidade de se deslocar lá fora, em meio a tantos obstáculos: a multidão, o trânsito, o lixo, o medo. O espaço da relação, do amor, do encontro não consegue se destacar em meio à velocidade e à angústia de existir na cidade, que parece engolir seus habitantes. É como se houvesse uma disputa na rua, onde novas construções se empilham em meio às antigas, delineando novos contornos para o horizonte que, estranhamente, parece reproduzir uma mesma paisagem. Seria esse um retrato dos ditos modos de vida pós-modernos?

Teria Porto Alegre também virado as costas para seu rio, ${ }^{1}$ como indaga Martin à sua Buenos Aires no filme $\mathrm{Me}$ dianeras (2011)?² Com águas impróprias para o banho e um pôr do sol que não cansa de ser enaltecido por seus habitantes, o Guaíba tem uma ligação histórica, cultural e afetiva com a cidade de Porto Alegre. Desde a chegada dos primeiros imigrantes portugueses a suas margens na então vila de Porto dos Casais, seu contorno e suas águas ajudaram a dar forma à cidade e a construir suas próprias narrativas. Águas que saciam a sede, refrescam, cheiram mal, trazem desenvolvimento, avançam sobre a cidade ou são "empurradas" para longe. Trazem sedimentos à cidade, necessidade de transformação, mudanças. Águas que demonstram o quanto as cidades são um campo de forças e formas em constante movimento e construção, um território vivo e afetivo, espaço de criação, de linhas de forças que se cruzam e se engendram, às vezes constituindo diferenças, às vezes atualizando antigas paisagens.

\footnotetext{
${ }^{1}$ Personagem de muitas discussões e controvérsias, o Guaíba é considerado por alguns habitantes de Porto Alegre um rio, e por outros, um lago. Com uma área de $496 \mathrm{~km}^{2}$, suas águas banham a extensão que vai do centro à extrema zona sul da cidade.

${ }^{2}$ Filme de 2011, dirigido por Gustavo Taretto, que mostra o cotidiano solitário de dois jovens, Martin e Mariana, na capital argentina em meio à cultura virtual e à arquitetura de Buenos Aires.
}

Nesse sentido, não se trata aqui de falar da cidade como um objeto a ser desvendado, definido, controlado. A atenção está voltada para as forças que compõem a cidade, para os vetores que nela se agenciam, se fortalecem e se cristalizam, tornando-se, por vezes, massificadores e homogeneizantes. Há ainda as forças que podem se encontrar e gerar desencontros, novas rotas e traçados, carregados de singularidades e novas possibilidades. Martin e Mariana, os personagens do referido filme argentino, falam um pouco desses desacordos entre seus corpos e a cidade, os nexos e desconexos, o sofrimento, as fugas, as estratégias de sobrevivência de que lançam mão frente às dificuldades e às formas de vida que são convocados a reinventar. Em meio a suas fobias às multidões ou ao convívio social, trancafiados em seus apartamentos apelidados de "caixa de sapatos", equivalentes aos chamados kitnets, com apenas uma janela, rebelam-se e produzem intervenções no seu cotidiano em busca de inovações: através das medianeiras dos prédios, abrem novas janelas em seus apertados apartamentos para que possam experimentar novos horizontes. Novos encontros se abrem, novos ares sopram em distintos espaços.

O pesquisador, ainda estrangeiro entre as paisagens da grande cidade, cuja rotina parece cada vez mais lhe aprisionar, também se encontra com alguns sinais que o surpreendem, geram certo incômodo, desviando o olhar do caminho já conhecido. De repente, em meio aos espaços tão dados e banalizados da cidade, entre formas de vida há muito dispostas, intervenções urbanas parecem querer provocar esse status quo imposto pelo cinza, pelo concreto e pelo medo. Grupos, empresas, moradores, artistas e urbanóides vêm articulando ou se encontrando no intuito de promover diferentes intervenções que usam as fissuras da cidade e, ao mesmo tempo, provocam novas fissuras, novos movimentos, novas narrativas dos/nos espaços. O imperativo do movimento, encontrado nas errâncias da cidade, ou em sua própria dureza, parece repentinamente quebrado e se mostra diferente. Por vezes, estas intervenções escapam do controle e padronização urbanísticos, por outras integram grandes projetos de intervenção no espaço urbano.

Por isso, o foco deste texto estará na experiência da cidade e suas errâncias, nas irrupções desses fluxos, nos desacordos entre esses corpos e seus cenários, que se dão em acontecimentos imprevisíveis e singulares (JEUDY; JACQUES, 2006) e que talvez bradem por resistências em meio às capturas da urbe. A ideia é explorar os efeitos de algumas intervenções urbanas que dizem propor novas formas de habitar a cidade. Por meio de um devir errante, busca-se captar e construir uma narrativa acerca dessas intervenções urbanas, com as quais o corpo do pesquisador esbarrou em sua despretensiosa errância por Porto Alegre, e seus efeitos sobre os modos de vida na cidade. Efeitos de subjetivação.

\section{Uma metodologia narrada nas errâncias}

Deleuze (2006) nos oferece uma maneira de compreender a cidade baseada no nomadismo e na captação das linhas de fuga do desejo na cidade. Afirma que a lógica 
do caos presente na urbe pede por um vislumbre atencioso de suas singularidades, pelas quais podemos extrair bifurcações e ressingularizações de formas de vida.

Em sintonia com tais ideias, Jacques (2006) defende uma apropriação do espaço público diferente: seu interesse está pelo que escapa do controle urbanístico e seus projetos, como um campo disciplinar. Quer buscar nas errâncias essa apropriação de modo a fundar um estado de corpo errante. É uma experimentação da cidade através de suas errâncias, "que se preocupa mais com as práticas, ações e percursos, do que com as representações gráficas, planificações ou projeções" (JACQUES, 2006, p. 118). Não é uma visão da cidade vista de cima, mas de dentro, mergulhada na experiência, a partir do que Deleuze entende por devir errante. Essa defesa parte de sua crítica aos métodos difundidos da disciplina urbanística que se apegam a dados estatísticos, objetivos e genéricos de análise da cidade e que culminam em uma espetacularização da cidade que cada vez mais se distancia da experiência urbana. Assim, faz do errar um instrumento para a experiência urbana, uma ferramenta subjetiva e singular que faz apologia à experimentação da cidade e que pode ser praticada por qualquer um.

A autora toma emprestado de Certeau (1998) a proposta de uma prática que se dá no andar pela cidade, que vai para além da experiência do percurso, do percorrer, do deslocamento urbano, mas que envolve um saber subjetivo, lúdico e amoroso. O andarilho é a forma elementar dessa experiência, pois seu "corpo obedece às plenitudes e descontinuidades de um texto urbano que eles escrevem sem poder ler" (CERTEAU, 1998, p. 171). Em movimento, a cidade é lida pelo corpo que escreve uma espécie de "corpografia" da cidade em que o foco está nas ações e vivências, não nas representações visuais. Constitui-se, assim, uma memória urbana no corpo de uma cidade que precisa ser tateada, ouvida, respirada, captando toda sua complexidade, enquanto um mero olhar consegue apenas dar contorno às imagens. É, portanto, através da própria vida urbana que se denuncia tudo o que escapa ao controle do mesmo, aquilo que os projetos não previram, as micropráticas de apropriação dos espaços. Como nos lembra Deleuze (2006), essa apropriação nos permite pensar em "habitar" um território, o que difere de apenas ocupá-lo. O habitar requer uma invenção, uma postura de criação frente ao espaço, enquanto o ocupar não passaria de uma mera vivência do já dado, daquilo que já está estabelecido e não é estranhado.

Barros e Kastrup (2009) fazem uma relação interessante entre o caminhar e a pesquisa cartográfica. Assim como a caminhada se faz num movimento contínuo de passos que se sucedem sem uma separação entre eles, a pesquisa cartográfica pressupõe esse ritmo de passos contínuos. É diferente, neste sentido, das concepções modernas da ciência, que separam os diferentes momentos da pesquisa (coleta, análise, discussão de dados, etc.), impondo um ordenamento e a conclusão de uma etapa para o início da outra. A cartografia traz o olhar da processualidade da pesquisa, já que cada momento traz consigo o anterior e se prolonga nos momentos seguintes.
Alinhado à perspectiva cartográfica, o pesquisador-errante seguiu seu percurso com a disposição de "praticar a cidade", já que, como Jacques (2006), entende que são os praticantes, e não os urbanistas, os responsáveis por indicar e atualizar os usos possíveis dos espaços projetados. A partir das improvisações e apropriações daqueles que habitam, passam, erram e reinventam os espaços, há a legitimação ou não desses projetos. Certeau (1998, p. 202) diz que "o espaço é lugar praticado. [...] a rua geometricamente definida pelo urbanismo é transformada em espaço pelos andarilhos (praticantes)."

Na mesma perspectiva, Benjamin (1987a, p. 73) trata da dificuldade do perder-se na cidade: "Saber orientar-se numa cidade não significa muito. No entanto, perder-se numa cidade, como alguém se perde numa floresta, requer instrução". Ainda mais em tempos em que quase todos carregam um GPS em suas mãos! É uma indicação que vai contra toda a lógica de orientação que o urbanismo nos apresenta, bem como um enfrentamento ao ritmo veloz imposto pela contemporaneidade que deve ser freada pelo andarilho, encontrando na lentidão a qualificação de sua errância. Opondo-se à clássica maneira da ciência de deduzir o todo pelas semelhanças, o autor propõe a figura do flâneur (BENJAMIN, 1994), essa outra postura calcada no detalhe, na lentidão, na diferença, no furo da totalidade. Knijnik (2009, p. 88-89) diz que a atenção do flâneur está nas fissuras, nos cacos, nos fragmentos de conversas, leituras e espaços:

No meio da multidão, o flâneur não grita seu nome para escapar ao anonimato. Recolhe os ruídos da cidade grande que fazem sua voz inaudível e faz de seu corpo um instrumento musical por onde tudo que passa ecoa, misturando-se novamente à multidão. Sem procurar por nenhuma identidade perdida, ao percorrer uma esquina, extrair um caco de palavra urbana na voz de um passante ou a textura de uma história inconclusa, resta-lhe montar-si em uma escrita andante. Sua pele é tecido urbano. Por isso o flâneur cria-si, monta-si...

O flâneur permite um resgate do cotidiano na constituição da experiência, a qual, para Benjamin, sempre se dará de forma coletiva e embebida por tradições, conselhos e transmissão de sentidos. Experiência que permita captar-se o movimento, falar-se e olhar com, e não sobre alguma coisa. Essa forma de ver a experiência, para o autor, encontra-se atrofiada na modernidade devido à sucessão de choques e informações aos quais a humanidade é exposta e que impossibilitam uma real apropriação daquilo que se passa.

É desse modo que Benjamin esclarece a "atrofia da experiência": através de uma sucessão cada vez maior de choques, a modernidade concede à experiência apenas uma modesta parte - se comparada ao que era antes -, legando à vivência a primazia da existência. Em razão dos choques proporcionados pela vida na cidade e de outras interferências no caráter da experiência, tais como o trabalho industrial, a modernidade é vista por Benjamin como uma época onde a "conscientização" é a sua maior marca (LIMA; BAPTISTA, 2015). 
É nesse sentido que Benjamin vem alertar para o fim da experiência (Erfahrung), pois é dela que se extrai a matéria para a construção das tradições e das narrativas, sejam elas privadas ou coletivas. Assim, possui um caráter mais rico, inconsciente, que flui na memória. Já a vivência (Erlebnis) forma-se por elementos mais isolados, presos à consciência, à memória e ao intelecto; uma experiência mais pobre, característica da modernidade (BENJAMIN, 1994). O filósofo quer resgatar as situações que se dão de maneira mais espontânea, sensível e, por que não dizer, errante, como fonte de construção de experiências, em contraponto a vivências, que estão mais presas a padronizações, opacidade e planificações da modernidade consciente e positivista.

Nesse distanciamento de uma lógica de orientação, de controle e previsão dos passos de uma pesquisa a que as metodologias tradicionais se propõem, mais uma vez a cartografia vem ao encontro dos princípios da errância. Passos, Kastrup e Escóssia (2009) explicitam o quanto a metodologia, em sua etimologia, impõe-se como uma palavra de ordem: meta-hódos. A pesquisa é definida como um caminho (hódos) predeterminado pelas metas dadas de partida. Entretanto, a cartografia quer reverter essa lógica, transformando o meta-hódos em hódos-metá:

Essa reversão consiste numa aposta na experimentação do pensamento - um método não para ser aplicado, mas para ser experimentado e assumido como atitude. Com isso não se abre mão do rigor, mas se é ressignificado. O rigor do caminho, sua precisão, está mais próximo dos movimentos da vida ou da normatividade do vivo, de que fala Canguilhem. A precisão não é tomada como exatidão, mas como compromisso e interesse, como implicação na realidade, como intervenção (PASSOS, KASTRUP; ESCÓSSIA, 2009, p. 10).

Semelhante ética na pesquisa é ressaltada por Spink (2008), segundo o qual o investigador social se constitui na prática diária, e não em uma lista de itens que devem ser averiguados a fim de garantir uma postura ética e moral aos olhos da boa ciência. Ele critica, ainda, a preocupação da psicologia social atual com os métodos enrijecidos, questionários, objetivos e termos de consentimento informados, que desconectam a pesquisa do cotidiano em nome do reconhecimento e da produtividade acadêmica. Seria o equivalente a um movimento de "jogar o holofote sobre os vaga-lumes", criando situações artificiais para se construir um conhecimento sobre uma vida também artificial, ou talvez expropriada de suas singularidades.

$\mathrm{O}$ autor quer chamar a atenção para a importância do acaso diário, dos encontros e desencontros, do falado e do ouvido em espaços cotidianos como filas, bares, salas de espera, corredores, escadarias, elevadores, estacionamentos, bancos de jardins, feiras, praias, banheiros e outros lugares de breves encontros e de passagem. Quer "recuperar a noção da psicologia social como prática social, de conversa e de debate, de uma inserção horizontal do pesquisador nos encontros diários" (SPINK, 2008, p. 70). Milhares de microlugares compõem o cotidiano de forma densa e muito diferente de um contexto eventual ou um cenário. São produtores e produtos de muitos processos sociais e subjetivantes, construídos de forma co- letiva e permanente. Estar no cotidiano é vivenciar uma inserção caótica no mundo, diferente do especialista ou do observador imparcial, fazendo com que o pesquisador seja atuante, se conecte com os fluxos das pessoas, dos espaços, dos objetos, da cidade, pois faz parte de um processo contínuo de negociação, resistência e imposição de sentidos coletivos.

Assim, trilhando um caminho metodológico que não ignora sua processualidade, mergulhando no cotidiano e fazendo da errância um guia, o pesquisador-errante percorre a cidade de Porto Alegre focando seu interesse em intervenções urbanas planejadas ou não, interferências que insurgem no caos urbanos e seus escapes. E é com a ajuda da cartografia, "esse desenho que acompanha e se faz simultaneamente aos movimentos da paisagem" (MIZOGUCHI, 2012, p. 54), que se produzem diferentes narrativas acerca da temática das intervenções urbanas, seja pelo encontro/desencontro com os espaços, seja pelas ressonâncias e repercussões na cidade e suas mídias. Intervenções urbanas que passam pelo corpo do pesquisador-errante, alteram sua trajetória, possibilitam uma experiência na cidade e não apenas uma aplicação de técnicas. O corpo torna-se superfície de acontecimentos (FOUCAULT, 1979). São essas intervenções que fazem este corpo indagar sobre carros, semáforos, ocupações, desaparecimentos, acontecimentos e rastros. A cartografia se apresenta como uma possibilidade de acompanhar esses rastros, de se construir narrativas abertas e que seguem uma proposta de desmontagem, isto é, um "plano de dissolvência" e "aumento de quantum intensivo" de um caso (PASSOS; BARROS, 2009, p.162), e não de afirmação de certezas assépticas e conclusões generalistas.

Nesse sentido, retomando as ideias de Benjamin (1987b), cabe ressaltar essa defesa do filósofo por narrativas que permitam criar possibilidades de se enunciarem novas narrativas, e não uma narração que se foque apenas em um objetivo à sua frente. Para ele, devido ao já mencionado declínio da experiência, as narrativas estão em crise na modernidade, quase em extinção. A arte de contar histórias, os conselhos, a narrativa tradicional, parecem ter perdido seu espaço em meio às produções textuais de sua época, principalmente os romances e a informação. Como ressalta o autor:

Contar histórias sempre foi a arte de contá-las de novo, e ela se perde quando as histórias não são mais conservadas. Ela se perde porque ninguém mais fia ou tece enquanto ouve a história. Quanto mais o ouvinte se esquece de si mesmo, mais profundamente se grava nele o que é ouvido. Quando o ritmo do trabalho se apodera dele, ele escuta as histórias de tal maneira que adquire espontaneamente o dom de narrá-las. Assim se teceu a rede em que está guardado o dom narrativo. E assim essa rede se desfaz hoje por todos os lados, depois de ter sido tecida, há milênios, em torno das mais antigas formas de trabalho manual (BENJAMIN, 1987b, p. 205.)

Preocupado com a transmissão dos ensinamentos que passam de narrador a narrador e constituem a sua obra final, Benjamin (1987b, p. 198) afirma no trecho acima que "a experiência que passa de pessoa a pessoa é a fonte a que recorrem todos os narradores", numa "temporalidade 
comum a várias gerações" (GAGNEBIN, 1999, p. 57). A narração é um trabalho artesanal, que sempre agrega um elemento de seu narrador à experiência a ser transmitida, atualizando e fusionando coletivamente as informações que, inconscientemente, julgar que podem ser úteis num futuro. Esta forma de contar histórias encontra maior potência quando transmitida oralmente, quando é performática, no encontro entre corpos, e não presa às regras de uma escritura, mesmo que esta última dê margem ao leitor para sentir a voz daquele que a escreve. O narrador tradicional deve saber que seu corpo se faz medianera a uma narrativa e sua transmissão, sempre aberta a outras possibilidades. Pesquisar aqui é errar, narrar, experimentar. E vamos às andanças!

\section{Errando pela cidade: potências de um carro-canteiro}

"Corpo: sangue embalado para viagem", era o que dizia o cartaz ${ }^{3}$ colado no poste, bem no início da rua em que o pesquisador-errante costumeiramente passa em direção à sua casa. É uma rua de apenas três quadras, nem muito calma, nem muito movimentada. Um trajeto já viciado do pesquisador, já revisitado tantas vezes diariamente que parece não conseguir conter a possibilidade da novidade ou da diferença. O cotidiano carrega uma mesmice, insignificâncias, embora também esteja cheio de inesperados, iminências, envolvendo os sujeitos numa bolha em que os milhares de movimentos parecem se tornar imóveis, onde nada parece acontecer, ao mesmo tempo em que tudo acontece. Está na hora de ir para casa. Todos estão indo para suas casas. Todos se deslocam. Tudo está igual como sempre. Visto sua fragilidade, "a bolha de ar pode ser desfeita a qualquer minuto" (CHIARA, 2007), seja por um cartaz, por um encontro, por um acontecimento.

A rua, na verdade, é uma avenida, mas uma avenida diferente, que não comporta o grande fluxo de trânsito no qual geralmente as avenidas encontram sua função. Há apenas duas pistas, uma para quem vai e outra para quem vem, deixando espaço junto às calçadas para os carros ficarem estacionados. Característico das avenidas, o canteiro no meio do traçado da rua está ali para dividir as pistas, além de outras utilidades: para o pedestre é uma pausa segura ao atravessar a rua; para as plantas e árvores é um espaço de terra fértil para desenvolverem-se e protegerem a rua do sol forte; para aquilo que não se quer mais é um espaço para ser ocupado por quinquilharias, velharias, doações... ou lixo.

A rua é bastante arborizada, tem calçadas largas, algum comércio e prédios residenciais, porém poucas casas. Oito containers distribuídos em sua extensão tentam dar conta do lixo produzido. Desde a mudança de status de "beco" à "avenida", pelo qual passou durante a urbanização da cidade, tornou-se uma importante via de ligação entre o bairro e o centro. Despercebido pelo pesquisador até então, seu início e seu fim são marcados pela presença de pequenas praças e semáforos. Praças com mais árvores, bancos para os cansados e famintos, fontes secas, brinquedos enferrujados para as crianças. Espaços

${ }^{3} \mathrm{O}$ cartaz remete a uma página do Facebook intitulada: “Amanual de formação de um desescritor" (NARDI, 2016). de exceção, pontos de pausa e breve calmaria em meio à agitação da cidade em que os semáforos insistem em lembrar que aquela via é de passagem, de movimento. Passar, e não parar. Seu nome? O de algum homem: desembargador, general, escritor, cuja história e prováveis conquistas e importância sejam desconhecidas ou foram esquecidas por aqueles que ali passam ou que ali moram.

À noite, as árvores dão um ar mais sombrio à avenida, embora alguns restaurantes e bares lancem suas luzes e ruídos para a via, agora mais calma e vazia. Alguns dizem achá-la perigosa, outros afirmam que se sentem totalmente seguros percorrendo sua extensão. $\mathrm{O}$ perigo estaria nas ruas perpendiculares. Alerta-se: "Nas travessas sempre pode ter alguém esperando pra te assaltar!". O cuidado e a atenção parecem ser sempre uma boa opção, mesmo dos mais corajosos, pois o risco é sempre presente, "ainda mais se der bandeira pela rua!". Vislumbrado apenas pelas luzes e sombras nas janelas dos apartamentos, o íntimo do lar é sinônimo de segurança.

Uma das travessas que cortam a avenida tem um diferencial: trata-se de uma escadaria. Vista de longe, os azulejos coloridos colados aos degraus transformam-na num grande mosaico, decorando a via que dá acesso a um conjunto de prédios antigos e habitados, até alcançar a rua acima. Nos azulejos, desenhos de notas musicais, crianças e armas, além de poemas e depoimentos dos moradores, compõem o visual, rememorando as diferentes situações ali experenciadas: saudade das brincadeiras das crianças nas escadas, a ajuda dos vizinhos, os gritos dos assaltos. ${ }^{4}$

Alguns mendigos e moradores de rua já são conhecidos dos que por ali costumam passar. Fazem das marquises dos prédios as suas casas, com a ajuda de papelão, colchões e cobertores velhos e sujos. Carrinhos de supermercado tornam-se seus mais preciosos pertences. Casas-móveis, livres, onde carregam tudo de que precisam, ou tudo aquilo que têm. Dormem até tarde do dia, em meio aos barulhentos motores de carros e buzinas. Um sono pesado, que não se sabe a que horas começou: se ainda na calada da noite ou somente ao amanhecer, quando a luz do sol volta a deixar a rua mais segura. Eles parecem se sentir seguros, tranquilos, conhecem a região. Estão em casa. Será que sonham? Quais serão seus sonhos?

E mesmo com toda uma rotina já estabelecida na avenida e a sensação de um incessante repetir de fatos já esperados, a rua consegue ter suas surpresas. Um carro queimado está estacionado. O corpo do pesquisador-errante se surpreende com aquela cena e quase como num automatismo se indaga, já propondo uma explicação: “será que foi um acidente?". Porém o carro não está amassado, apenas queimado. Seu interior está vazio, provavelmente consumido pelas chamas, e grande parte da lataria está à mostra. Dianteira e traseira do automóvel estão intactas, com exceção da pintura levemente des-

\footnotetext{
${ }^{4}$ Inspirada na escadaria Seleron do Rio de Janeiro, a referida escadaria é palco constante de intervenções artísticas e cenário de mostras fotográficas que compõem a cultura arquitetônica da cidade. Mais informações disponíveis em: https://siteantigo.portaleducacao.com.br/conteudo/artigos/marketing/escadaria-da-rua-24-de-maio-porto-alegre-rs-estudo-do-lugar-e-das-percepcoes/55767
} 
cascada. Restos de borracha denunciam que ainda tinha pneus. É um carro antigo, sem placa, abandonado e meticulosamente estacionado.

Muitas inquietações começam a borbulhar na mente do pesquisador: "O que aquele carro fazia ali? Quem era o dono? Ele estaria à procura do carro? Estaria preocupado? Como chegou ali? Como conseguiu aquelas marcas? Como pegou fogo? Seria a prova de um crime?". Não se sabe. Ninguém sabe. É lixo, é resto, é o que sobrou e alguém não quis, como tantas outras coisas que se abandonam por aí. Permanece ali semanas, meses, aparentemente intocado. Esquecido? Não! O carro tinha uma história, ao menos tinha que ter uma história, assim como aquela avenida, cheia de marcas, sinais e rastros de seus transeuntes.

Um pouco mais adiante do tal carro, existe uma lojinha já tradicional na rua, cujo proprietário é muito bem informado dos acontecimentos da vizinhança. É ele quem conta que aquele carro está ali há muito tempo, provavelmente abandonado pelo dono. Os vizinhos até já tinham pedido para que a prefeitura o recolhesse, mas nunca ninguém apareceu e nenhuma outra providência foi tomada. Passaram-se meses, até surgirem alguns interessados naquele objeto de valor, que, àquela altura, parecia ter se transformado em um mero entulho estorvando a rua e tirando espaço para outros carros estacionarem. Algo tão estimado em tempos em que vagas de estacionamento parecem ter sumido. Mendigos e moradores de rua começaram a fazer do carro um local seguro para dormir, talvez morar, habitar.

É nesse momento que algumas forças da cidade parecem ganhar mais visibilidade, como se a rua tivesse algumas leis próprias, não muito claras aos moradores das casas e apartamentos da avenida. Forças que se intensificavam à noite e que materializavam cada vez mais as disputas por aquele espaço que carregava um valor nem sempre visível: espaço de moradia, espaço de convivência, vaga de estacionamento, espaço de segurança. Brigas, discussões, gritos no calar da noite. Quem teria aquele espaço? Quem poderia usá-lo? Quantos podem entrar no carro? Quem deve ou não estar ali? Forças que culminam em um incêndio. Não se sabe se causado por moradores da rua, ou moradores de rua. Mas sabe-se que agora ninguém mais moraria ali, tampouco estacionaria.

$\mathrm{O}$ tempo passou rápido, como é peculiar às cidades, $\mathrm{e}$ o carro ali permaneceu. Agora queimado, vidros quebrados. Autoridades, moradores, seu antigo dono, ninguém queria saber daquele monte de lata e fuligem. Deixa estar... De repente a pintura descascada parecia ter sido retocada. A fuligem tinha virado terra. O preto incendiado estava colorido. O carro agora parecia bem-humorado. Não era mais um carro queimado e abandonado. Agora era um canteiro, uma horta, carregado de pequenas plantas, flores e temperos. Cheio de vida...

$\mathrm{Na}$ calada da noite, na calmaria de um fim de semana, mãos anônimas transformaram um monte de latas em um monte de cores e cheiros. Desprezado, ignorado, disputado, queimado e reinventado. $\mathrm{O}$ objeto que a princípio se fazia intruso na rua, de carcaça queimada, passa a ser uma marca daquela rua, a fazer parte dela. Os moradores (de rua e da rua) gostavam dele assim. Os passantes também. Ninguém conseguia deixar de reparar naquele carro, agora alegre. Tinham que parar para olhar, não mais simplesmente passar. Ele pertencia à rua de um jeito diferente. De carro esquecido, passou a ser um carro para esquecer a rotina daquela rua e tentar inaugurar novas. Rotinas que envolviam novos diálogos, encontros entre vizinhos, pedestres e curiosos, fotografias, cultivo de cheiros e gostos, outros olhares.

Nas redes sociais e pelas caixas de correio, os moradores da rua ficaram sabendo do café da manhã coletivo que iria acontecer ali. Cada um levaria um prato para socializar com os vizinhos, além de sua própria xícara ou caneca, para evitar o uso de copos plásticos. Bandeiras coloridas ajudaram a decorar a rua, que, fechada aos carros durante cerca de três horas, pôde receber moradores, velhos conhecidos, curiosos, antigos e novos vizinhos. Foram distribuídas ao redor do carro, perto da escadaria, mesas dobráveis, toalhas coloridas e cadeiras de praia. Até mesmo um sofá foi para a rua, proporcionando maior conforto e organização aos participantes do evento. Ocupar a rua possibilitou encontros, abriu conversas, proporcionou trocas e empréstimos para além das xícaras de açúcar.

Um dia o carro sumiu. Ficaram apenas algumas plantas inclassificáveis por entre as pedras e o asfalto. Mas logo aquele espaço foi ocupado por outro carro. E depois outro, e outro. Dessa vez eles eram modernos, pintados, brilhantes e bem fechados. Ninguém dormia dentro deles e, à noite, dificilmente alguém ficava por ali. Era perigoso! A surpresa e o espanto daqueles que se surpreendiam com o antigo carro agora se manifestava por sua falta. " $O$ que aconteceu?" - perguntavam-se todos. O dono da lojinha, mais uma vez, tinha a resposta. Finalmente, a prefeitura tinha feito alguma coisa com aquele carro queimado que ficava ocupando espaço e gerava confusão na rua. "Levaram!" - disse ele, não escondendo a frustração de ter perdido parte daquela rua, parte de si, juntamente com a partida do carro. Seu pensamento ressentido não conseguia sair de um mesmo círculo: "O movimento da loja certamente cairia. As crianças não brincariam mais por ali. As pessoas não tirariam mais fotos. A senhora do prédio da frente não buscaria mais o manjericão".

Algo semelhante já tinha acontecido algumas quadras mais adiante, mas dessa vez em uma grande e movimentada avenida de quatro pistas. Em uma incessante tentativa de se atravessar a tal avenida, o pesquisador-errante encontrou um parklet $t^{5}$ construído pelos alunos do curso de arquitetura da Universidade Federal do Rio Grande do Sul, em frente ao prédio da faculdade (MAGS, 2014). O objetivo era produzir uma discussão sobre os espaços da cidade e chamar a atenção para a valorização dos pedestres e a falta de espaços de convivência. Em meio a preocupações da direção do curso com a segurança dos alunos (sob a afirmação de que a iniciativa não tinha qualquer envolvimento com a faculdade), críticas de al-

${ }^{5} \mathrm{O}$ parklet é um espaço de convivência que fica instalado sobre as vias públicas. Nesses locais, pelo menos duas vagas de estacionamento recebem uma plataforma móvel, que pode ser equipada por bancos, mesas, guarda-sóis, aparelhos de exercícios físicos ou elementos com função de recreação ou manifestação artística. 
guns passantes, que reclamavam estar perdendo quatro vagas de estacionamento, e confusões burocráticas que almejavam a regularização da estrutura junto aos órgãos administrativos responsáveis, na madrugada de um fim de semana qualquer, a estrutura sumiu. Comoção da comunidade acadêmica, pedidos de ajuda e seguidas reportagens no jornal levaram ao encontro do material, cerca de uma semana depois, em um depósito do órgão responsável pelo trânsito da capital. Após uma denúncia anônima, que dizia haver sucata atrapalhando o fluxo de trânsito na via, e sem saber do que se tratava e nem de quem era aquele material, os fiscais haviam recolhido as peças (GIACOMELLI, 2014).

São situações que parecem buscar em elementos e espaços comuns da cidade novas formas de pensá-la e habitá-la. O carro-canteiro foi um novo personagem que deu outro ritmo àquela avenida, para além do ritmo imposto pelos semáforos. O parklet também criou um novo tempo-espaço numa avenida movimentada que não permite obstáculos em seu percurso. Atravessar a rua ali pode ser um grande desafio, uma grande epopeia. Pedestres e carros disputam o mesmo espaço, mais uma vez marcado pelo semáforo, nem sempre respeitado. Disputa de forças que aqui não geram incêndios, mas que estão marcadas no asfalto pelas borboletas, são lembradas pelas bicicletas brancas acorrentadas nos postes, pelos índices de acidentes e mortes no trânsito, que crescem. A vida na cidade pode ser curta. O tempo é curto. Vidas aprisionadas em um tempo que parece não tirar o pé do acelerador.

O tempo é um dos elementos de destaque nas análises do filósofo alemão Walter Benjamin, no que diz respeito às metrópoles modernas. Ele se afasta de uma perspectiva histórica progressiva, ou presa a uma imagem do passado, para propor a construção de uma experiência com o pretérito (GAGNEBIN, 2012), evidenciando "uma oportunidade de recuperação do inacabamento do passado" (FERREIRA, 2012, p. 154). Para ele, nas cidades contemporâneas existe um "tempo devorador, que impossibilita que uma anterioridade se agregue ao presente, empurrando os homens a uma vivência sem expectativa de compartilhamento coletivo" (FERREIRA, 2012, p. 161). São cidades pautadas por um tempo de produção maquínica, carregado de automatismos que alimentam uma concepção de tempo progressivo que nunca para de avançar e se traduz de forma hegemônica em um tempo social que encontra moradia no relógio. Um tempo que não permite encontros, não permite pausas, nem perdas de tempo, que ignora os rastros do passado.

Assim, diante de uma época em que a vivência individual parece triunfar, fruto de modos de produção cada vez mais velozes, informações espetacularizadas, vazias e pontuais, e romances com heróis previsíveis, Benjamin busca resgatar a experiência, sempre coletiva, como forma de resistência a uma modernidade que impede o ser humano de digerir as mudanças frente ao avanço desenfreado da técnica e do ritmo que ela impõe (SILVA, S., 2014). Retomando o trabalho artesanal, as narrativas orais e a tradição (vista aqui não como uma imposição do passado, mas como um aconselhamento, uma trans- missão da experiência), Benjamin almeja que o indivíduo não perca sua capacidade de se reconhecer no mundo, cada vez mais individualista e pobre de experiências que permitam laços sociais (BENJAMIN, 1994). Não é à toa que o autor usa a figura do flâneur e seu animal de estimação, a tartaruga, para sustentar uma postura calcada na lentidão, no detalhe, na diferença, nas inconstâncias em meio à padronização, com o propósito desse resgate.

\section{À guisa de conclusão: pausas e encontros possíveis}

Um caminho já sem sentido, envolto em um cotidiano anonimizador, torna-se palco de inúmeras intervenções urbanas que parecem resgatar a potência da experiência. Desde um cartaz que instaura um olhar estrangeiro no pesquisador-errante, até carros-canteiros que transformam afetos e espaços, as intervenções urbanas parecem se fazer acontecimentos. Acontecimentos que, como diria Deleuze (1982), abrem um campo problemático que requer novos entendimentos e sentidos, fogem do previsto, geram intriga e produção de novos sentidos (LANA; FRANÇA, 2009). As intervenções urbanas produzem pausas no incessante movimento das ruas. Desaceleração do tempo e dos corpos. Possibilidades de parar, sentar, encontrar, respirar, cultivar. Dissipam o medo das ruas, do espaço público.

A partir dos restos, montes de lixo, latarias queimadas e enferrujadas, caixotes indesejados, rastros que constantemente se tenta apagar, as intervenções conseguem captar intensidades do passado, germes de uma outra história que podem ser transmutados em outras narrativas para a cidade e seus habitantes. Captam os murmúrios da rua e abrem um limiar, uma zona de passagem que permite romper com a bolha do cotidiano, voltar o olhar para a constelação dessa bolha, dar impulso a um pulo para fora dela, instaurando sobre ela uma nova consciência. A experiência liminar sempre vai ser acontecimental, pois reúne as condições que permitem a existência de algo novo.

Diferente da fronteira, uma linha que demarca oposições, o limiar é uma faixa mais larga, uma zona que conjuga todo um passado e um futuro em uma oportunidade (BARRENTO, 2012), num kairós, isto é, num tempo relâmpago dos acontecimentos, possibilitando um início, uma gênese. Dessa forma, as intervenções urbanas tentam deixar novas marcas na cidade já tão saturada de imagens chocantes. Marcas coletivas, que promovam um reconhecimento comum e estejam sempre abertas à criação, à invenção.

A senhora que morava em frente à loja não se deu por vencida com o sumiço do carro-canteiro. Aproveitou o dia de sol para plantar algumas sementes de temperos no espaço de terra sem calçamento, entre as pistas da avenida. Julgou que ali havia uma boa sombra e a dose necessária de sol. $\mathrm{O}$ dono da loja, mergulhado em seu ressentimento, quase depressivo desde que o carro sumira, invejou a iniciativa da senhora: "Duvido que essas sementes germinem!". Mas em poucos minutos se pôs a ajudá-la. Ela aproveitou para lhe contar o quanto aqueles temperos tinham-na feito retomar seu gosto pela cozinha. Estava devendo um bolo para a vizinha no início da rua, 
desde o café da manhã coletivo. Assim que os temperos estivessem crescidos, o faria. O dono da loja, só sorria e ouvia. Enquanto isso, os jornais anunciavam uma reunião entre autoridades e possíveis parceiros que discutiria a instalação de parklets em alguns bairros da cidade.

\section{Informações sobre os autores:}

\section{Guilherme Augusto Flach \\ (iD) https://orcid.org/0000-0002-8192-2984 \\ (9) http://lattes.cnpq.br/8520590692488613}

Psicólogo graduado pela Pontifícia Universidade Católica do Rio Grande do Sul (2011). Especialista em terapia de família e casal pelo Centro de Terapia DOMUS/FACCAT e Mestre em Psicologia Social e Institucional pela Universidade Federal do Rio Grande do Sul. Colaborador do grupo de pesquisa INTERVIRES: PesquisaIntervenção em Políticas Públicas, Saúde Mental e Cuidado em Rede do Instituto de Psicologia da UFRGS. Tem experiência na área de Psicologia Clínica (família, casal e individual) e sexualidade/ gênero, em pesquisas na área da saúde mental com metodologia qualitativa (pesquisa-intervenção) e em políticas de subjetivação nas cidades contemporâneas.

\section{Simone Mainieri Paulon \\ (iD) https://orcid.org/0000-0002-0387-1595 \\ (9) http://lattes.cnpq.br/6053363307031981}

Psicóloga (PUCRS), especialista em Psicologia Social (PUCRS), com mestrado em Educação (UFRGS), doutorado em Psicologia Clínica (PUC-SP) e pós-doutorado no PPG de Psicologia UFRN com estágio de professora visitante no Dipartimento di Psicologia,dell?Alma Mater Studiorum, Università di Bologna. É professora associada da Universidade Federal do Rio Grande do Sul, na qual orienta trabalhos de pesquisa e extensão junto ao laboratório de Políticas Públicas do departamento de Psicologia Social e Institucional, ao PPG de Psicologia Social, e coordena grupo INTERVIRES: Pesquisa-Intervenção em Políticas Públicas, Saúde Mental e Cuidado em Rede. Integra o corpo docente do PPG de Psicologia Institucional da Universidade Federal do Espírito Santo (UFES). Compõe o Grupo de Trabalho "Políticas de Subjetivação e Invenção do Cotidiano" da Associação Nacional de Pesquisa e Pós-graduação em Psicologia (ANPEPP). Atua como editora associada da área de saúde mental junto à Revista Interface Comunicação, Saúde e Educação. Tem experiência na área de Psicologia e Saúde Coletiva, com ênfase em Intervenção Terapêutica e Saúde Mental.

\section{Contribuição dos autores:}

Os autores colaboraram ao longo do processo, desde a elaboração até a revisão final do manuscrito. Ambos aprovaram o manuscrito final para publicação.

\section{Como citar este artigo:}

\section{ABNT}

FLACH, Guilherme Augusto; PAULON, Simone Mainieri. Um olhar errante sobre as intervenções urbanas em Porto Alegre. Fractal: Revista de Psicologia, Niterói, v. 33, n. 3, p. 173-181, set./ dez. 2021. https://doi.org/10.22409/1984-0292/v33i3/5802

\section{APA}

Flach, G. A., \& Paulon, S. M. (2021, Setembro/Dezembro). Um olhar errante sobre as intervenções urbanas em Porto Alegre. Fractal: Revista de Psicologia, 33(3), 173-181. doi: https://doi. org/10.22409/1984-0292/v33i3/5802

\section{Copyright:}

Copyright (C) 2021 Flach, G. A., \& Paulon, S. M. Este é um artigo em acesso aberto distribuído nos termos da Licença Creative Commons Atribuição que permite o uso irrestrito, a distribuição e reprodução em qualquer meio desde que o artigo original seja devidamente citado.

Copyright (C) 2021 Flach, G. A., \& Paulon, S. M. This is an Open Access article distributed under the terms of the Creative Commons Attribution License, which permits unrestricted use, distribution, and reproduction in any medium, provided the original article is properly cited.

\section{Referências}

BAPTISTA, Luis Antonio. O veludo, o vidro e o plástico: desigualdades e diversidade na metrópole. Niterói: EdUFF, 2009.

BARRENTO, João. Walter Benjamin: limiar, fronteira e método. Olho d'água, São José do Rio Preto, v. 4, n. 2, p. 4151, 2012. Disponível em: http://www.olhodagua.ibilce.unesp. br/index.php/Olhodagua/article/view/146. Acesso em: 22 abr. 2017.

BARROS, Laura Pozzana de; KASTRUP, Virgínia. Cartografar é acompanhar processos. In: PASSOS, Eduardo; KASTRUP, Virgínia; ESCÓSSIA, Liliana da. (Org.). Pistas do método da cartografia: pesquisa-intervenção e produção de subjetividade. Porto Alegre: Sulina, 2009. p. 52-75.

BENJAMIN, Walter. Infância em Berlim por volta de 1900. In: . Rua de mão única. Tradução de Rubens Rodrigues Torres Filho e José Carlos Martins Barbosa. São Paulo: Brasiliense, 1987a. Obras Escolhidas, v. 2, p. 9-69.

BENJAMIN, Walter. Magia e técnica, arte e politica: ensaios sobre literatura e história da cultura. 3. ed. São Paulo: Brasiliense, 1987b. Obras escolhidas.

BENJAMIN, Walter. O flâneur. In: . Charles Baudelaire: um lírico no auge do capitalismo. 3. ed. Tradução de José Carlos Martins Barbosa e Hemerson Alves Baptista. São Paulo: Brasiliense, 1994. Obras escolhidas, v. 3, p. 185-236.

CERTEAU, Michel. A invenção do cotidiano: artes de fazer. Petrópolis: Vozes, 1998.

CHIARA, Ana. No mês do cavalo. In: LOPES, Denilson. $A$ delicadeza: estética, experiência e paisagens. Brasília: UnB, 2007. p. 11-16.

DELEUZE, Gilles. Lógica do sentido. São Paulo, Perspectiva, 1982.

DELEUZE, Gilles. A ilha deserta e outros textos: textos e entrevistas (1953-1974). Organização de David Lapoujade. Tradução de Luiz B. L. Orlandi. São Paulo: Iluminuras, 2006.

FERREIRA, Marcelo Santana. Walter Benjamin e a cidade. In: BAPTISTA, Luis Antonio; FERREIRA, Marcelo Santana (Org.). Por que a cidade? Escritos sobre a experiência urbana e a subjetividade. Niteroi: EdUFF, 2012. p. 153-168.

FOUCAULT, Michel. Microfisica do poder. Tradução e organização de Roberto Machado. Rio de Janeiro: Graal, 1979.

GAGNEBIN, Jeanne Marie. História e narração em Walter Benjamin. 2. ed. São Paulo: Perspectiva, 1999. 
GAGNEBIN, Jeanne Marie. Prefácio: Walter Benjamin ou a história aberta. In: BENJAMIN, Walter. Magia e técnica, arte e política: ensaios sobre literatura e história da cultura. 7. ed. Tradução de Sérgio Paulo Rouanet. São Paulo: Brasiliense, 2012. p. 8-19.

GIACOMELLI, Ana Karina. Encontrado parklet que desapareceu da frente da Faculdade de Arquitetura da UFRGS. Jornal Zero Hora, Porto Alegre, 29 out. 2014. Disponível em: http://zh.clicrbs.com.br/rs/noticias/noticia/2014/10/ encontrado-parklet-que-desapareceu-da-frente-da-faculdadede-arquitetura-da-ufrgs-4631320.html. Acesso em: 28 abr. 2015.

JACQUES, Paola Berenstein. Elogio aos errantes: a arte de perder-se na cidade. In: JEUDY, Henri Pierre; JACQUES, Paola Berenstein (Org.). Corpos e cenários urbanos: territórios urbanos e políticas culturais. Tradução de Rejane Janowitzer. Salvador: EDUFBA/FAUFBA, 2006. p. 117-140.

JEUDY, Henri Pierre; JACQUES, Paola Berenstein (Org.). Corpos e cenários urbanos: territórios urbanos e políticas culturais. Tradução de Rejane Janowitzer. Salvador: EDUFBA/ FAUFBA, 2006.

KNIJNIK, Cristiane. Cacos urbanos: gesto, cidade e narração. 2009. Dissertação (Mestrado) - Programa de Pós-graduação em Psicologia, Universidade Federal Fluminense, Niterói, 2009.

LANA, Lígia Campos de Cerqueira; FRANÇA, Renné Oliveira. Do cotidiano ao acontecimento, do acontecimento ao cotidiano. E-Compós, [S. 1.], v. 11, n. 3, 2009. Disponível em: https://www.e-compos.org.br/e-compos/article/view/303. Acesso em: 12 abr. 2017.

LIMA, João Gabriel; BAPTISTA, Luis Antonio. Itinerário do conceito de experiência na obra de Walter Benjamin. Principios: Revista de Filosofia, Natal, v. 20, n. 33, p. 449-484, 2015. Disponível em: https://periodicos.ufrn.br/principios/ article/view/7526. Acesso em: 12 out. 2020.

MAGS, André. Estudantes da UFRGS instalam parklet em frente à Faculdade de Arquitetura. Jornal Zero Hora, Porto Alegre, 24 out. 2014. Disponível em: http://zh.clicrbs.com.br/ rs/porto-alegre/noticia/2014/10/estudantes-da-ufrgs-instalamparklet-em-frente-a-faculdade-de-arquitetura-4628272.html. Acesso em: 28 abr. 2015.

MEDIANERAS: Buenos Aires na Era do Amor Virtual. Direção: Gustavo Taretto. Buenos Aires: Eddie Saeta et al., 2011. 1 DVD (95 min).

MIZOGUCHI, Danichi Hausen. Segmentaricidades: passagens do Leme ao Pontal. São Paulo: Plêiade, 2009.

MIZOGUCHI, Danichi Hausen. Equivocidade: passagens entre pensamentos. In: BAPTISTA, Luis Antonio; FERREIRA, Marcelo Santana (Org.). Por que a cidade? Escritos sobre a experiência urbana e a subjetividade. Niteroi: EdUFF, 2012. p. 53-64.

NARDI, Nicolas. Amanual de formação de um desescritor. Facebook. 27 dez. 2016. Disponível em: https://m.facebook. com/amanualdeformacaodeumdesescritor/?fref=ts \& rdr. Acesso em: 12 jun. 2019.

PASSOS, Eduardo; BARROS, Regina Benevides de. Por uma política da narratividade. In: PASSOS, Eduardo; KASTRUP, Virgínia; ESCÓSSIA, Liliana da (Org.). Pistas do método da cartografia: pesquisa-intervenção e produção de subjetividade. Porto Alegre: Sulina, 2009. p. 150-171.
PASSOS, Eduardo; KASTRUP, Virgínia; ESCÓSSIA, Liliana da. Pistas do método da cartografia: pesquisa-intervenção e produção de subjetividade. Porto Alegre: Sulina, 2009.

SILVA, Rodrigo Lages e. O que são essas luzes. In: BAPTISTA, Luis Antonio; FERREIRA, Marcelo Santana (Org.). Por que a cidade? Escritos sobre experiência urbana e subjetividade. Niteroi: EdUFF, 2012. p. 15-29.

SILVA, Simone Carlos da. Uma análise contextual da filosofia: entre desvios e conceitos. Cadernos Walter Benjamin, v. 12, p. 1-16, 2014.

SPINK, Peter Kevin. O pesquisador conversador no cotidiano. Psicologia \& Sociedade [online], v. 20, n. spe, p. 70-77, 2008. https://doi.org/10.1590/S0102-71822008000400010 